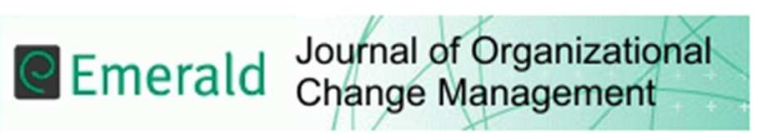

\title{
Recognizing patterns of organizational change after flexible individualization
}

\begin{tabular}{|r|l|}
\hline Journal: & Journal of Organizational Change Management \\
\hline Manuscript ID: & JOCM-01-2015-0010 \\
\hline Manuscript Type: & Editorial \\
\hline & \\
\hline
\end{tabular}

SCHOLARONE ${ }^{m}$

Manuscripts 


\title{
Recognizing Patterns of Organizational Change after Flexible Individualization
}

\author{
Slawek Magala, Erasmus University Rotterdam, smagala@rsm.nl \\ Francisco Liñán, University of Seville, flinan@us.es
}

\begin{abstract}
Organizational change is a complex phenomenon and has always been, but one that is
\end{abstract} becoming increasingly important as recombining of human individuals and other organizational resources begins to enter a daily schedule of managerial activities. Organizations, as all of us have already found out working in professional bureaucracies, need to adapt to increasingly faster changes in their environment. Obviously, managers and their organizing and managing practices are not immune to the quick transformation in societies forcing all participants in the flows of interactions and communications to adapt. Needless to say the ways we all act are influenced by the way we think. And the ways we think emerge from a dense jungle of interaction and communication processes, in which what we feel and desire can matter more than what we calculate and rationalize (Magala, 2012). Both feelings and desires are the outcome of social interactions, in which culturally shaped communications are pervasive. No theory of organizational change is complete without mentioning the role of cultural shift in persuading and seducing corporate citizens in order to implement a successful change project. The prevailing narratives usually rest on a number of unquestioned assumptions about the nature of social reality, the meaning of history and the desired direction of change (Magala, 2012).

In particular, our way of thinking about leadership and control has dramatically changed in recent years. No one leadership style is fully applicable across all cultures, and leadership as a practice can only be understood as part of a complex system of societal processes and cultural communications. Thus, as markets move more into globalization, and companies respond by following multinational, international, or global strategies, the workforce of most of the companies tends to become increasingly diverse (McLaurin, 2008).

Thus, organizations change, managing routines evolve, cultural legitimacy of change policies or managerial techniques evolves. At the same time, authoritarian control erodes, democratic participation proceeds by trials and errors, one step forwards, two steps backwards, new communication and information technologies expand our horizontal networks sideways, often spurning hierarchies and their radioactive fallouts. We all feel that contemporary organizational change depends crucially on three types 
of processes, which twist together in unpredictable flows of organizational transformations.

First, political leadership is perceived as a coaching with a charismatic flavor, not as a brutal imposition of a single will on docile and hierarchically frozen employees, citizens, consumers, masses. To lead is to serve and to fill the media with an aura. Traditional political leadership in liberal democracies has produced political structures that are both complex and opaque. The many spheres of political leadership -party, government, civil society' s associations - coexist, interact, reinforce and neutralize one another (Rhodes \& Hart, 2014). However, recent events have shown the weaknesses of such an approach. At the organizational level, leadership undergoes similar pressures. Led organizations must be open, otherwise Wikileaks will undermine them. How will open leaders accumulate charisma? Is Ricken Patel of Avaaz.org a premonition of things to come? Or Malala Yousafzai?

Second, organizing and managing is adapted to individual mobility and horizontal networking at the expense of lines of command. Information and communication technologies allow substantially wider collaboration and team work, with equally increased accountability and evaluation (Anderson, 2014). Why not a more egalitarian design, why not a democratic veto of pyramids and knowledge hoarding? Accumulation of decision-making power or knowledge is inferior to their exchange. Open platform and inclusion are better than proprietary knowledge and ACTA. More flexitime work/life balance? Sabbaticals as a remedy against unemployment and a premature slipping down into comfortable routines?

Third, people refuse to follow standard pattern of professional and organizational socialization. Individuals hold multiple identities simultaneously. The self-concept consists of multiple identities that vary along dimensions including their centrality or importance to the individual, whether they reflect actual or potential achievement, and their temporal orientation (Mainemelis, Altman, Ibarra, \& Petriglieri, 2010). One size does not fit all. Standards get customized. Docility is out, criticism is in. An individual should be able to identify, assess and oppose servers or persuaders as he or she sees fit (say, contemporary equivalents of a Bernays, who sent millions of women to a cancerous death promising them a liberation by smoking in public).

These three change processes jointly act to cause new changes in the patterns of organizational change. Teams, networks, knowledge brokers, crowd sourcing, actionable knowledge retooled for 3D printers at every corner. Not only Shells, also state elites are challenged by activists (Greenpeace on behalf of mankind vs Russian Federation on behalf of the post-Soviet power elite), Popes push for democratization of the Catholic Church. The environment organizations will face tomorrow is far from known and certainly not predictable. And the most suitable organizational design, the 
one which could allow organizations to succeed in this environment, may only be laboriously crafted in a trial-and-error process.

The four papers included in this special issue analyze this process of transformation in organizational change from different angles. Thus, the first of them, by Sune and Gibb, explores the managerial processes involved in deep, purposeful organizational change. They focus on a longitudinal case study on the airline Spanair during the period 20012012 , one of the most turbulent in the history of aviation. The company had to undergo radical transformation to try to avoid bankruptcy, but was not successful. In this context, the paper aims at identifying patterns of organizational change in trying to achieve this change towards a goal directed end state and the managerial actions involved in reaching it, understanding how variations occurred in a firm's resources and capabilities at a time of high internal and external uncertainty. The paper identifies a capability pattern with four dynamic capabilities: adding, transferring, integrating and shedding; and two higher-order capabilities: goal development and change orchestration. We show how the higher-order capability processes are performed by two levels of decision makers, where one creates a goal directed path, and the other performs a central role in orchestrating change. It shows how the role of management becomes fundamental, but it also emphasizes the importance of providing bottom-up advice to goal directors.

The paper by Lowe et al., in turn, discusses the interactive processes linking lived embodied experiences, language and cognition (body-talk-mind) and their implications for organizational change. The authors find that participants used embodied metaphors in a number of ways (positive and negative connotations) in different contexts (single or multicultural groups) for different purposes. Using an analogy, participants could be said to be cooking up realities according to who was at the table. Embodied metaphors may be useful as they capture descriptions of reality that stimulate reflexivity, uncover suppressed organizational problems and promote the contestation of received wisdoms when organizational change is pressing and urgent.

The third paper, by Rodríguez-Gutiérrez et al., focuses on growth as a key organizational change. In particular, it analyses the resources and capabilities that may become sources of competitive advantage in Spanish services-industry SMEs. This issue has been analyzed exhaustively for the manufactured goods industry, but has scarcely been addressed for the services industry. The findings reveal that the entrepreneur's characteristics, firm features and managerial attributes all have significant effects on the business performance. In particular, business factors concerning the Entrepreneurial Orientation of the firm condition its competitive success.

Finally, the contribution by Poprawski focuses on culture education organizations. The purpose of the paper is to identify and discuss structure, essence and quality of current 
organizational frameworks for the arts and culture, institutions, NGO's and enterprises that are core playgrounds for flexible individualization of taste, cultural literacy, individuals' expressions and their cultural identity. The topic of flexible individuation of taste in relations to culture education institution practices, is reflected in a complementary approach, from a triadic perspective of cultural policy, marketing and aesthetics, bringing new insights for organization change research and practice.

Overall, therefore, the special issue offers four different perspectives on the newly emerging patterns of organizational change. We are confident readers will find these approaches as enriching and complementary. They answer several important questions but, what is even more important, they pose new unsolved questions that future research may address.

\section{References}

Anderson, D.L. (2014). Organization development: The process of leading organizational change: Sage Publications.

Magala, S.J. (2012). Organizing change: testing cultural limits of sustainability. Management Decision, 50(5), 900-908. doi: doi:10.1108/00251741211227582

Mainemelis, C., Altman, Y., Ibarra, H., \& Petriglieri, J.L. (2010). Identity work and play. Journal of Organizational Change Management, 23(1), 10-25. doi: doi:10.1108/09534811011017180

McLaurin, J.R. (2008). Leader-effectiveness across cultural boundaries: An organizational culture perspective. Journal of Organizational Culture, Communication and Conflict, 12(1), 49-69.

Rhodes, R.A.W., \& Hart, P.t. (2014). Puzzles of political leadership. In R. A. W. Rhodes \& P. t. Hart (Eds.), The Oxford Handbook of Political Leadership (pp. 1-22). Oxford, UK: Oxford University Press. 